\title{
Study on the Construction of Mobile E-commerce Platform of Changsha YT Enterprise
}

\author{
Zhengxin $\mathrm{Wu}$ \\ Hunan Modern Logistics College \\ Changsha, China 410131
}

\author{
Jing Zhong* \\ Hunan Modern Logistics College \\ Changsha, China 410131 \\ *Corresponding Author
}

\begin{abstract}
Facing the situation where mobile e-commerce is in a great prosperity, this article, aiming at the significance and basic principle for making a mobile e-commerce platform for Changsha YT enterprise, discusses the mobile e-commerce platform-related software function, technical maturity, reliability and implementation plan, which are considered as basis for the platform making.
\end{abstract}

Keywords—mobile e-commerce; executive plan; research

\section{INTRODUCTION}

Facing the situation where IT and online economy are in a great progress, e-commerce has been gradually becoming a major commercial mode for enterprises. In the meantime, based on mobile communication technologies and Internet technologies, mobile Internet is developing at a high speed and more and more mobile terminals having access to mobile Internet are spreading rapidly, a mobile e-commerce, which is a combination of mobile communication network and Internet, has become the core for E-commerce advancement. It is expected by many experts that the mobile E-commerce will be becoming a mainstream mode for E-commerce in the future.

\section{SOCIAL AND ECONOMIC SigNifiCANCE}

Having a feature as mobile, e-commerce makes it easy for communicate with clients anytime and anywhere, fully embodying the philosophy of clients-targeted, satisfying client's individuation and diverse service, which will do good to improve clients' loyalty and provide clients with convenient, flexible and quality service, it is expected to be mainstream for e-commerce development in the future and bring large social and economic value.

On one hand, the e-commerce platform at Changsha YT enterprise, based on client relation management (CRM) and supply chain management (SCM), can provide clients and suppliers with product information, service anytime and anywhere, which help to perfect communication, gain more clients and maintain sound cooperation so as to create a good external environment for the company; On the other hand, according to production arrangement on the basis of work flow systems, the company can manufacture products as per orders so as to keep the production going efficiently; meanwhile, relying on enterprise resource management system (ERP), it can grasp all data related to its inventory, spare parts and assure the zero inventory. Going like this, the company runs in a completely closed environment, able to accurately and immediately get all information existing in the closed system, efficiently arrange production and manage the enterprise so that it can adapt itself to any situations in a hot market competition and developing at a high speed. Accordingly with the setting up and expansion of mobile e-commerce platform at Changsha YT enterprise, it will be sure to bring huge social and economic benefits.

Specifically, main social and economic significance of the platform include:

- Set up a perfect CRM system to conduct uniform control upon the company's operation, marketing and client service, helping the company catch market chances, form marketing strategies and accelerate market responses; promote active marketing and gain more chances and ways for sales; conduct control and smart analysis on clients, grasp what clients need and maintain clients' loyalty.

- Maintain sound cooperation with supplies via SCM system and improve partners' management. Amid modern economy, sound cooperation is a key element for enterprise to succeed and an important condition for its sustainable development.

- The production arrangement system based on work flow will promote the production flow automation, reduce labor involvement, achieve highly and accurately controls on data flow, improve the enterprise's work efficiency, eliminate meaningless error, perfect work flow, shorten production period and achieve terminal to terminal automation.

- Relying on the ERP system, it can conduct systematic control on enterprise resources and spare parts, promote inventory management, and achieve the zero inventories, less costs and efficient operation.

- Relying on portal management, it can adopt Portal technique to satisfy clients' individuation, making it easy for clients' operation. 
All in all, the mobile e-commerce platform at Changsha YT enterprise can meet clients' need in individuation and mobile service, improve clients' loyalty, making the company exist in a highly efficient and well running closed environment, which will be certainly bring it huge economic benefits. With the platform software expanded gradually, it will be sure to produce huge social and economic value and advance the mobile e-commerce in the country.

\section{BASIC PRINCIPLES}

Amid a mobile e-commerce, a client can use a mobile terminal having access to mobile Internet to engage in all kinds of e-commerce operation on the basis of wireless terminal, WAP gate between wireless network and Internet, necessary verifications, safety technique as well as relevant payment modes and logistics systems.

The mobile e-commerce platform at Changsha YT enterprise provides clients with individual access via enterprise portal, and conducts uniform control on operation, sales and clients service via CRM system, make use of workflow to achieve the terminal to terminal production arrangement automation, and achieve the integrated management and arrangement on inventories and product resources via resources management; Achieve zero inventory, and conduct controls on supplies and partners via SCM system, and create smart analysis and decision making systems via techniques like data mining so as to get reliable basis for enterprise management; in the meantime, amid the system, a data center EDC is borrowed to conduct centralized management on core data, raise the system's openness and expandability, and the whole system will become a clients-targeted terminal to terminal automation closed system.

\section{SOFTWARE FunCTIONS OF MOBILE E-COMMERCE PLATFORM FOR CHANGSHA YT ENTERPRISE}

\section{A. Enterprise Portal}

Achieving individualized service for mobile clients: on one hand, a client can customize "pull" service of his own; on the other hand, information is pushed to clients as per smart decision-making systems, which will be accepted by clients.

\section{B. Enterprise Website}

Establish XML-based dynamic category management and information release, after being integrated to CRM systems and sound interactions, enterprise website can launch product and service marketing to clients.

\section{Crm System}

\section{1) Marketing Sub-system}

a) Market information managing: Collecting and archiving marketing information databases, keep normal communications inside and outside systems, create and manage market information database and make sure it could be well used.

b) Marketing plans managing: Grasping marketing chances, set up and supervise marketing plans. c) Marketing activity management: Marketing activity scheme design, conduct management on marketing activity database, marketing activity implementation marketing activity evaluation.

d) Product design and management: Product type and process flow design and management.

2) Selling sub-system

a) Information release: release product category information via XML.

b) Online purchase: produce customized products as per what clients need.

3) Client service sub-system: Standardize clients' complaints, suggestions and declaration to analyze the information process, find the focus and improve service.

\section{Production Scheduling}

Achieve terminal to terminal automation service, and produce batch-customized products according to the needs of customers.

\section{E. ERP}

Conduct efficient management on enterprise resources, achieving zero inventories.

\section{F. SCM}

Achieve joint purchases: suppliers can get information online, knowing what enterprises need; and the enterprise may release purchase order to suppliers via SCM.

\section{G. Smart Decision Making}

Based on BI analysis and decision making of clients and suppliers, product and demand information can be pushed to clients and suppliers, which will support the enterprise's management and decision making.

\section{H. Systematic Management}

- Access control: click to $\log$ on

- Safety control: access to database

\section{External Interface}

- Interfaces with CA verification center and online payment center in CRM

- Interface with suppliers in SCM

- Interface with logistics centers

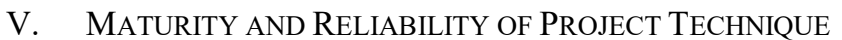

\section{A. Development Technique}

Project development platform is SUN ONE (Open Network Environment) owned by SUN, which is a crossplatform development environment. Based on JAVA, it is open and expandable. It is a combination of Portal Server, Directory Server and Application Server, of which, Portal Server is used for achieving the enterprise portal, meeting clients' 
individualized demands; Directory Server is used to record and register clients' information, speeding up the logging on speed; Application Server achieves the J2EE-based layer-N component structure of distributed servers, doing good to repeated component use and achieve thin client structure. It is very reliable and mature for the platform which has been widely used in telecom field and distributed application in enterprises.

XML technique: attentions have paid to data access and conversion, and a lot of researches have been made in ecommerce field and telecom, which proves reliable.

Project's system analysis and design: borrow object oriented technique and RUP-based software engineering technique, which are the most advantageous system analysis and design in project developments.

Middleware: borrowing SUN's Message queue, it is well integrated to SUN ONE platform and used in diverse field development.

Workflow: During the terminal to terminal automation service, more and more workflows are adopted, which is popular currently.

\section{B. Project Management}

The company has years of experience in e-commerce software, OA software and CRM software development.

\section{Personnel}

Those engaged in the project development and management all own solid theoretical bases and rich experience in project development. They have made specific analysis on what the project needs and targets.

\section{IMPLEMENTATION PLAN}

\section{A. Technical Plan}

First of all, based on systematic survey and research, the project adopts the object oriented OOA and OOD for systematic analysis on demands and design, with RUP used for system modeling; it gives a multi-layer components framework for distributed servers of mobile e-commerce platform for Changsha YT enterprise, make information modeling for core data; with system modules used, conduct EJB components development, debugging and tests aimed at the system prototype. Finally based on needs of enterprises in diverse fields, corresponding software are researched and developed and marketed.

- Adopt object-oriented OOA and OOD for systematic analysis on demands and design, with RUP used for modeling to ensure the system construction under control.

- The project $R \& D$ are centered on the system structure, focused on the design of the same, inter-operation design and component functions so as to place a solid foundation for system prototype design.
- Workflow, cooperating, data center and smart commerce are introduced to the project $R \& D$ in order to achieve the system's terminal to terminal automation, strengthen the system cooperation, intelligence and openness.

\section{B. Production Plan}

The mobile e-commerce platform of Changsha YT enterprise will be independently produced by our company. With the market expanded, the company will have its scales expanded further, it is predicted that the large scale production of the project products in 2004. According to clients need and market feedback, the mobile e-commerce system software products markets will be developed in many fields in 2004, our production will be further increased, keeping a higher market share continuously.

\section{Marketing Plan}

The system will be sold to enterprises and mobile users at home, aimed at manufacturers and purchasers and salesmen next year. With the production scale expanded gradually, Changsha YT enterprise, based on the project product $R \& D$, will develop mobile e-commerce system software for enterprises, and the marketing mode shall adopt direct selling and product agencies.

\section{Solutions for Other Problems}

During the system research and drafting implementation plan, there are no other problems arising. If any problem arises out of the system development, implementation or production, solutions will be made as per what the problem is.

\section{CONCLUSION}

The Changsha YT enterprise's mobile e-commerce platform software developed by Changsha YT enterprise considers the current situations of mobile e-commerce at home, aiming to develop mobile e-commerce platforms for enterprises with clients centered, market guided in order to meet clients' individualized and diverse needs. As far as technique, it adopts layer $\mathrm{N}$ system framework of advanced distributed server, achieving thin clients, which meet the situation of mobile client with slow CPU and lower memory; during the production scheduling, workflow is adopted to achieve the terminal to terminal automation; data center and smart commerce are borrowed for centered data control and smart analysis on decision making, as well as introducing object oriented and software engineering systematic analysis and design. The system is a combination of marketing, production and supply, which is a software product integrating CRM, ERP, SCM, workflow and production scheduling, and its design thought and methods all meet what mobile ecommerce at home need, having obvious innovation and pioneering spirits. 


\section{REFERENCES}

[1] Xu Rongrong, Research on Modern Mobile E-commerce Modes-based on Mobile Taobao [J]. China Circulation Economy, 2017(24). (in Chinese)

[2] Zhang Xueli, Research on Mobile E-commerce Modes in China [J]. The Farmers' Consultant, 2017(22). (in Chinese)

[3] Wong Junfei, Thoughts of Mobile E-commerce Development [J]. Modern Economic Information, 2018(03). (in Chinese)

[4] Zhu Xiufen, Discussion on Mobile E-commerce Development Modes in China [J]. Journal of Commercial Economics, 2018(14). (in Chinese) 